\title{
Q Seleção de cultivares de cana-de-açúcar potenciais para o município de Lavras - sul de Minas Gerais
}

\author{
Luciane Reis Sales ${ }^{1}$ \\ Luis Eduardo Villar Cesar ${ }^{2}$ \\ Adriano Teodoro Bruzi ${ }^{3}$ \\ José Airton Rodrigues Nunes 4 \\ Luiz Antônio de Bastos Andrade 5 \\ Maurício Ferreira Lopes $^{6}$
}

\section{Resumo}

A cultura da cana-de-açúcar desempenha um papel econômico importante na região de Lavras, Minas Gerais, onde é cultivada sem muito aporte tecnológico e com cultivares não adaptadas às condições edafoclimáticas locais. O objetivo deste trabalho foi avaliar cultivares de cana-de-açúcar quanto ao potencial produtivo agroindustrial na região sul de Minas Gerais, bem como estudar a associação entre os caracteres agronômicos e industriais no primeiro corte. $O$ experimento foi conduzido no município de Lavras/MG, onde foram avaliadas 16 cultivares recomendadas para a indústria sucroalcooleira, em delineamento experimental látice quádruplo 4 X 4. Os resultados apresentados demonstraram que houve uma grande variabilidade genética entre as cultivares, proporcionando a formação de vários grupos de caracteres agroindustriais para os genótipos avaliados. Os genótipos que apresentaram um maior teor de fibra reduziram, ao mesmo tempo, a produção e a qualidade da matéria-prima da cana-de-açúcar. As cultivares SP891115, RB925211 e CTC9 foram as que apresentaram melhor desempenho quanto aos caracteres agroindustriais TCH, Pol, Fibra e ATR, e poderão ser indicadas para o cultivo comercial na região de Lavras.

Palavras-chave: Saccharum spp. Produção. Correlação. Índice de seleção.

\section{Introdução}

O Brasil é o maior produtor mundial de cana-de-açúcar (Saccharum spp). A área cultivada com essa espécie na safra de 2013/14 foi de aproximadamente 8,81 milhões de hectares e a produtividade média obtida foi de $74.769 \mathrm{~kg} \mathrm{ha}^{-1}$. Minas Gerais é o terceiro maior estado produtor, com 8,9\% da área plantada, o que corresponde a aproximadamente 780 mil hectares e produção em torno de 58 milhões de toneladas para o ano de 2014 (CONAB, 2014).

1 Universidade Federal de Lavras (UFLA), discente de Mestrado em Fitotecnia. Lavras, MG, Brasil. luciane lavras@yahoo.com.br. (35) 9119-9429. Campus Universitário da UFLA, Departamento de Agricultura, CEP: 37200-000, Caixa Postal 30̄37, Lavras, MG.

2 Universidade Federal de Lavras (UFLA), discente de Mestrado em Fitotecnia, Lavras, MG, Brasil. levcesar@uol.com.br. (65) 96158286. Campus Universitário da UFLA, Departamento de Agricultura, CEP: 37200-000, Caixa Postal 3037, Lavras, MG.

3 Universidade Federal de Lavras (UFLA), professor doutor do Departamento de Agricultura, Lavras, MG, Brasil. adrianobruzi@dag.ufla. br. (35) 3829-1301. Campus Universitário da UFLA, Departamento de Agricultura, CEP: 37200-000, Caixa Postal 3037, Lavras, MG.

4 Universidade Federal de Lavras (UFLA), professor doutor do Departamento de Biologia, Lavras, MG, Brasil. jarnunes@dbi.ufla.br. (35) 3829-1353. Campus Universitário da UFLA, Departamento de Biologia, CEP: 37200-000, Caixa Postal 1341, Lavras, MG.

5 Universidade Federal de Lavras (UFLA), professor doutor do Departamento de Agricultura, Lavras, MG, Brasil. laba@dag.ufla.br. (35) 3829-1312. Campus Universitário da UFLA, Departamento de Agricultura, CEP: 37200-000, Caixa Postal 3037, Lavras, MG.

6 Universidade Federal de Lavras (UFLA), discente de Mestrado em Fitotecnia, Lavras, MG, Brasil. mauricioagronomo@yahoo.com.br. (38) 9105-8113. Campus Universitário da UFLA, Departamento de Agricultura, CEP: 37200-000, Caixa Postal 3037, Lavras, MG. 
A cultura da cana-de-açúcar representa uma grande parcela da economia da região de Lavras, Minas Gerais, pois proporciona uma fonte de renda para muitos agricultores familiares por meio do cultivo para a produção de cachaça artesanal, forragem para a bovinocultura e produção de rapadura (ANJOS et al., 2007; CASTRO et al., 2009). A maior parte da produção dessa cultura na região é obtida em sistemas de cultivo de subsistência, que não fazem uso de tecnologias e utilizam, na sua maioria, cultivares tradicionais ou crioulas, com baixa adaptação ou pouco melhoradas.

Para regiões onde há áreas de cultivo da cana-de-açúcar que não dispõem de genótipos meIhorados para esses locais, Rodrigues et al. (2012) ressaltaram que se devem utilizar materiais adaptados a outras regiões, após avaliação experimental no local de plantio, para se obterem níveis de produtividade satisfatórios. Alguns autores, como Perecin et al. (2009), Rodrigues et al. (2012) e Andrade et al. (2002), ressaltaram que a base da sustentação da agroindústria canavieira é a cultivar de cana-de-açúcar, pois representa incrementos em produtividade sem grandes custos adicionais. Ressaltam ainda que deve haver um processo contínuo de substituição dos materiais utilizados em decorrência da degenerescência natural do genótipo ao longo do tempo.

Estudos envolvendo o crescimento e desenvolvimento de culturas agrícolas são importantes para a caracterização das espécies nos diferentes ambientes e sistemas de produção (NASIF et al., 2013). Para Melo et al. (2006), a avaliação de caracteres agroindustriais da cana-de-açúcar está diretamente relacionada com o desempenho produtivo de cada cultivar, razão pela qual é recomendável realizar experimentos para avaliar o crescimento, o desenvolvimento e a produtividade de diferentes genótipos cultivados em condições edafoclimáticas específicas. Segundo Andrade et al. (2002), para a identificação de cultivares potenciais de cana-de-açúcar, deve-se atentar para algumas características desejáveis, tais como: maior produção de colmos por hectare, alto teor de sacarose, teor de fibra médio, boa adaptação a diferentes tipos de solo e clima, boa brotação de soqueiras, rápido crescimento inicial e fechamento das entrelinhas, entre outros.

De acordo com Ramalho et al. (2012), a estratégia de se reunirem, simultaneamente, em uma mesma cultivar, vários fenótipos favoráveis para caracteres de interesse constitui um mecanismo estratégico vantajoso em programas de melhoramento. Nem sempre todos os caracteres têm a mesma importância para o trabalho de melhoramento, e a maioria dos caracteres pode ser correlacionada; portanto, trabalhar com vários caracteres ao mesmo tempo torna-se desafiador e exige muita eficiência no trabalho do melhorista.

Para Almeida et al. (2014), muitos genótipos de cana-de-açúcar são avaliados todos os anos em programas de melhoramento e tem sido cada vez mais difícil selecionar os melhores materiais fenotipicamente. Nesse sentido, o uso de métodos precisos de análise estatística é necessário para garantir uma maior confiabilidade no processo de seleção. Para a seleção simultânea de caracteres, existem algumas alternativas, entre as quais se destaca o método do índice de seleção de Mulamba e Mock (1978), usado com eficiência por Pedrozo et al. (2009) e Almeida et al. (2014) na cultura da cana-de-açúcar. Esse índice é obtido após o ordenamento dos genótipos quanto ao caráter avaliado, no sentido desejado, e posterior somatório das suas classificações.

Nesse contexto, objetivou-se com este trabalho, avaliar cultivares de cana-de-açúcar quanto ao potencial produtivo agroindustrial na região sul de Minas Gerais, bem como estudar a associação entre os caracteres agronômicos e industriais no primeiro corte. 


\section{Materiais e métodos}

O experimento foi conduzido no município de Lavras/MG, no campo de produção de cana-de-açúcar da empresa Bocaina Agroindústria e Comércio de Cachaça Ltda., localizada na rodovia BR265, km 349, a 920m de altitude, 2114' de latitude Sul e 4500' de longitude Oeste. De acordo com a classificação e as tendências climáticas propostas por Dantas et al. (2007), o clima de Lavras é do tipo Köppen (CWa), temperado chuvoso (mesotérmico), com inverno seco e verão chuvoso. 0 município apresenta uma média anual de precipitação pluvial de $1.530 \mathrm{~mm}$ e temperatura média anual de $22^{\circ} \mathrm{C}$.

Foram avaliadas 16 cultivares recomendadas para a indústria sucroalcooleira de diferentes procedências: CTC 1, CTC 2, CTC 7, CTC 8, CTC 9, CTC 14, CTC 15, CTC 16, RB925345, RB867515, RB855453, RB925211, SP813250, SP891115, SP801842, SP842025. Foi utilizado o delineamento experimental em látice quádruplo $4 \times 4$. 0 plantio foi realizado na segunda quinzena do mês de novembro de 2011 e a colheita em novembro de 2012, sendo a parcela experimental constituída de três sulcos de 5,0m, com espaçamento de 1,30m entre os sulcos.

O solo foi preparado em sistema convencional de cultivo, com a aração seguida de gradagem e a abertura dos sulcos feita por tração mecanizada. A calagem foi feita no sulco de plantio na dosagem de $2 \mathrm{t} \mathrm{ha}^{-1}$. Utilizaram-se $650 \mathrm{~kg} \mathrm{ha}^{-1}$ da formulação NPK 8-28-16 no sulco de plantio como adubação de base, feita de acordo com a análise físico-química do solo. Na adubação de cobertura, foram aplicados $500 \mathrm{~kg} \mathrm{ha}^{-1}$ e $250 \mathrm{~kg} \mathrm{ha}^{-1}$ de ureia, aos 30 e 60 dias após o plantio, respectivamente. 0 controle das plantas daninhas foi realizado por meio da aplicação, em pós-emergência, de herbicida à base dos ingredientes ativos 2,4-D (1,5 L ha-1) e Diuron $\left(2,5 \mathrm{~L} \mathrm{ha}^{-1}\right)$.

Os caracteres agronômicos avaliados foram: 1) número de colmos por metro linear (NC), obtido pela contagem total de colmos na fileira central, dividindo-se o valor total obtido pelo comprimento do sulco; 2) diâmetro médio de colmo (DC), obtido em mm, com o auxílio de um paquímetro digital, tomando-se o diâmetro de dez plantas ao acaso da linha central, na mesma altura, e calculando-se a média do valor obtido; 3 ) altura do colmo (AC), medida em centímetros, com o auxílio de uma trena graduada, do nível do solo até a inserção da primeira folha desenvolvida, tomando-se dez plantas ao acaso da linha central e calculando-se a média do valor obtido; 4) massa média de colmos (MMC), obtida por meio da pesagem, via balança, com precisão de $10 \mathrm{~g}$, de dez colmos despontados e despalhados, coletados aleatoriamente após a colheita das três linhas da parcela, posteriormente calculando-se a média do valor obtido; 5) toneladas de cana por hectare ( $\mathrm{TCH}$ ), colhendo-se todas as canas despontadas e despalhadas, das três linhas de cada parcela, posteriormente extrapolando-se o valor obtido por meio da transformação do peso total das parcelas em toneladas por hectare; 6) tonelada de Pol por hectare (TPH), obtida por meio do estimador: TPH $=(\mathrm{TCH} \times$ Pol\% cana)/100.

Para a determinação dos caracteres industriais, utilizaram-se os 10 colmos, tomados ao acaso, em cada parcela experimental, por ocasião da colheita, os quais foram enfeixados, etiquetados e encaminhados para o Centro Avançado da Pesquisa Tecnológica do Agronegócio de Cana - IAC/Apta, onde se realizaram as análises dos seguintes caracteres: 1) açúcar total recuperável (ATR), expresso em $\mathrm{kg} \mathrm{t}^{-1}$, obtido pela análise após inversão ácida de sacarose; 2) porcentagem aparente de sacarose contida no caldo de cana (Pol\% cana); 3) porcentagem de matéria insolúvel em água contida na cana (Fibra\% cana); 4) porcentagem de sólidos solúveis contidos no caldo extraído da cana (Brix\% caldo); 5) pureza aparente (Pureza\% caldo), sendo definida como a percentagem de Pol contida no Brix, ou seja, é um indicador da quantidade de açúcares em relação aos demais sólidos solúveis do caldo. 
Essas análises industriais foram realizadas de acordo com o Manual de Instruções do Conselho dos Produtores de Cana-de-açúcar, Açúcar e Álcool do Estado de São Paulo (CONSECANA, 2006).

Para os dados fenotípicos do experimento, empregou-se a análise com recuperação da informação interblocos com o aporte do pacote estatístico Statistical Analysis System (SAS, 1999), de acordo com o modelo apresentado a seguir:

$$
y_{\mathrm{ijk}}=\mu+\mathrm{r}_{\mathrm{j}}+\mathrm{b}_{\mathrm{k}(\mathrm{j})}+\mathrm{a}_{\mathrm{i}}+\mathrm{e}_{\mathrm{ijk}}
$$

onde:

$y_{i j k}:$ observação da parcela que recebeu o clone $i$ no bloco $k$ dentro da repetição $j$;

$\mu$ : constante associada a todas as observações;

$r_{j}$ : efeito fixo da repetição $j$;

$b_{k(j)}$ : efeito aleatório do bloco $k$ dentro da repetição $j$;

$a_{i}$ : efeito fixo do clone $i$

$e_{i j k}$ : erro experimental aleatório associado à observação $y_{i j k}$.

De posse das médias fenotípicas ajustadas dos clones, realizou-se o agrupamento pelo teste de Scott-Knott (1974), em nível de 5\% de significância, via software genético-estatístico Genes (CRUZ, 2006).

As estimativas das correlações fenotípicas mensuradas entre os caracteres foram obtidas de acordo com a expressão:

$$
r_{x y}=\frac{\operatorname{Cov}_{x y}}{\sqrt{V_{x} V_{y}}}
$$

onde:

$\operatorname{Cov}_{x y}$ : estimativa da covariância fenotípica entre as variáveis $x$ e $y$;

$V_{x}$ e $V_{y}$ : estimativas das variâncias fenotípicas médias das variáveis $x$ e $y$, respectivamente.

As análises de correlações também foram realizadas via software genético-estatístico Genes (CRUZ, 2006).

Para a seleção simultânea envolvendo os caracteres TCH, Pol\% cana, Fibra\% cana e ATR, adotou-se o princípio do índice de seleção de Mulamba e Mock (1978). A partir das médias fenotípicas ajustadas, atribuíram-se postos para as cultivares em cada caráter, de acordo com o interesse para a produção agroindustrial de cana-de-açúcar, ou seja, a fim de aumentar ou diminuir a expressão fenotípica do caráter. A partir dos postos dos clones para cada característica, procedeu-se à soma, obtendo-se os valores do índice para cada cultivar, de acordo com a expressão apresentada a seguir:

$$
I_{M M(i)}=\sum_{k=1}^{n} u_{k}=u_{1} r_{i 1}+u_{2} r_{i 2}+\ldots+u_{n} r_{i n}
$$

onde:

$I_{M M(i)}=$ valor do índice de Mulamba e Mock associado ao clone $i$;

$\mu_{k}=$ peso econômico do caráter $k$ (neste trabalho igual a 1 );

$r_{i j}=$ posto associado à média fenotípica ajustada da cultivar $i$ relativo ao caráter $k$.

Como medida de precisão experimental, adotou-se a acurácia seletiva, conforme estimador apresentado por Resende e Duarte (2007):

$$
r_{g g}=\sqrt{1-1 / F C}
$$


onde:

Fc é o valor do teste de F para o efeito das cultivares da análise de variância.

\section{Resultados e discussão}

Os resultados referentes à análise de variância estão apresentados na Tabela 1. Comprova-se que houve eficiência relativa do delineamento em blocos incompletos (látice) em relação ao delineamento em blocos casualizados completos (DBC) para a maioria dos caracteres avaliados, com exceção do caráter DC. Esse resultado demonstra que a estratégia de restrição à casualização adotada foi eficiente.

Tabela 1. Resumo da análise de variância para os caracteres Brix\% caldo, Pol\% cana, Fibra\% cana, açúcar total recuperável (ATR) em $\mathrm{kg} \mathrm{t}^{-1}$, Pureza\% caldo, número de colmos $\mathrm{m}^{-1}$ (NC), diâmetro médio de colmo (DC) em $\mathrm{mm}$, altura média de colmos (AC) em $\mathrm{cm}$, massa média de colmos (MMC) em $\mathrm{kg}$, tonelada de pol por hectare (TPH) e tonelada de cana por hectare (TCH) de dezesseis cultivares de cana-de-açúcar, avaliadas no município de Lavras, MG, na safra de 2012.

\begin{tabular}{|c|c|c|c|c|c|c|c|c|c|c|c|c|}
\hline \multirow[b]{2}{*}{$\begin{array}{c}\text { Fontes de } \\
\text { variação }\end{array}$} & \multirow[b]{2}{*}{$\mathrm{GL}$} & \multicolumn{11}{|c|}{ Quadrado médio } \\
\hline & & Brix & Pol & Fibra & ATR & Pureza & NC & DC & $A C$ & MMC & $\mathrm{TPH}$ & $\mathrm{TCH}$ \\
\hline Repetições & 3 & 0,47 & 0,51 & 0,54 & 43,87 & 1,81 & 6,28 & 14,5 & 1.091 & 0,06 & 2,7 & 3.275 \\
\hline $\begin{array}{c}\text { Blocos/ } \\
\text { Repetições }\end{array}$ & 12 & 0,64 & 0,94 & 0,4 & 79,27 & 2,73 & 5,37 & 0,98 & 662 & 0,04 & 11,5 & 9.666 \\
\hline Cultivares & 15 & 3,17 & 4,03 & 3,76 & 350,7 & 4,49 & 5,6 & 10,6 & 721 & 0,06 & 16,4 & 12.123 \\
\hline Erro efetivo & 33 & 0,31 & 0,38 & 0,35 & 32,56 & 0,89 & 0,22 & 2,7 & 416 & 0,03 & 5,9 & 5.639 \\
\hline Total & 63 & 1,03 & 1,33 & 1,18 & 115,2 & 2,06 & 4,9 & 4,8 & 545 & 0,04 & 8,9 & 7.500 \\
\hline Eficiência (\%) & & 119 & 129 & 101 & 127,5 & 143,5 & 101 & 83,1 & 108 & 103 & 116 & 110,7 \\
\hline $\begin{array}{l}\text { Acurácia } \\
\text { seletiva }\end{array}$ & & 94,9 & 92,0 & 90,9 & 92,09 & 89,53 & 96,0 & 64,7 & 65,1 & 70,1 & 80,0 & 58,79 \\
\hline F (Cultivares) & & $10 * *$ & $10 * *$ & $11^{* *}$ & $11^{* *}$ & $5,0 * *$ & $25^{* *}$ & $4^{* *}$ & $1,7^{\text {ns }}$ & $1,9^{\text {ns }}$ & $2,7 * *$ & $2,15^{*}$ \\
\hline
\end{tabular}

ns, * **, não significativo, significativo a $5 \%$ e a $1 \%$ de probabilidade, respectivamente, pelo teste $\mathrm{F}$.

Fonte: Elaboração dos autores.

As estimativas da acurácia seletiva variaram de 58,79\% (TCH) a 96,0\% (NC), no presente trabalho (Tabela 1). Para Resende e Duarte (2007) e Cargnelutti Filho et al. (2012), o parâmetro acurácia seletiva é adequado para avaliar a precisão experimental em ensaios de competição de genótipos de cana-de-açúcar, pois tem a propriedade de informar sobre o correto ordenamento das cultivares para fins de seleção. Na pesquisa aqui apresentada, os caracteres Brix, Pol, Fibra, ATR e $\mathrm{NC}$ apresentaram valores muito altos para a acurácia seletiva, enquanto os caracteres Pureza, MMC e TPH, valores altos e, por fim, os caracteres DC, AC e TCH, valores moderados, de acordo com a classificação proposta pelos autores. Além disso, Ferreira et al. (2007) afirmam que quando há significância estatística a 5\% de probabilidade no teste $\mathrm{F}$ dos genótipos avaliados, pode-se considerar a precisão das análises como adequada, o que foi evidenciado neste estudo para a maioria dos caracteres avaliados (Tabela 1 ). Esses valores de acurácia seletiva e do teste $F$ das cultivares demonstram uma boa precisão experimental durante a condução do experimento, o que favorece a detecção de pequenas diferenças estatísticas entre os genótipos e, por consequência, uma melhor confiabilidade nos resultados obtidos para a discriminação das cultivares. 
Foi identificada diferença significativa a $5 \%$ de probabilidade $(p<0,05)$ para o caráter TCH e a $1 \%$ de probabilidade $(p<0,01)$ para os caracteres Brix, Pol, Fibra, ATR, Pureza, NC, DC e TPH, o que evidencia que há variabilidade genética entre os genótipos avaliados. Resultado similar foi obtido por Melo et al. (2006, 2009), ao estudarem o desempenho de cultivares de cana-de-açúcar por meio de caracteres agroindustriais no primeiro corte. Como as cultivares avaliadas foram estatisticamente diferentes para esses nove caracteres, as médias foram testadas pelo método do teste de agrupamento proposto por Scott-Knott (1974), conforme apresentado na Tabela 2.

Tabela 2. Médias fenotípicas ajustadas para os caracteres Brix\% caldo, Pol\% cana, Fibra\% cana, açúcar total recuperável (ATR) em $\mathrm{kg} \mathrm{t}^{-1}$, Pureza\% caldo, número de colmos $\mathrm{m}^{-1}$ (NC), diâmetro médio de colmo (DC) em $\mathrm{mm}$, tonelada de pol por hectare (TPH) e tonelada de cana por hectare (TCH) de dezesseis cultivares de canade-açúcar, avaliadas no município de Lavras - MG, na safra de 2012.

\begin{tabular}{cccccccccc}
\hline Cultivar & Brix & Pol & Fibra & ATR & Pureza & NC & DC & TPH & TCH \\
\hline CTC 2 & $17,76 c$ & $16,53 c$ & $12,83 a$ & $160,88 c$ & $92,92 c$ & $8,80 b$ & $26,96 b$ & $07,38 b$ & $43,86 b$ \\
CTC 1 & $17,22 c$ & $16,17 d$ & $15,34 c$ & $157,09 c$ & $94,00 c$ & $6,90 d$ & $29,47 a$ & $05,16 b$ & $31,59 b$ \\
CTC 8 & $17,63 c$ & $16,45 d$ & $13,77 b$ & $159,96 c$ & $93,33 c$ & $7,25 d$ & $27,83 a$ & $05,07 b$ & $31,80 b$ \\
CTC 7 & $19,48 a$ & $18,53 a$ & $13,63 b$ & $179,34 a$ & $95,10 b$ & $8,70 b$ & $27,66 a$ & $09,21 a$ & $49,96 a$ \\
CTC 14 & $17,57 c$ & $16,47 d$ & $14,81 c$ & $160,02 c$ & $93,77 c$ & $9,75 a$ & $26,47 b$ & $08,08 b$ & $48,71 a$ \\
CTC 16 & $18,33 b$ & $17,36 c$ & $14,59 c$ & $168,25 b$ & $94,73 b$ & $10,30 a$ & $24,06 b$ & $06,45 b$ & $37,84 b$ \\
CTC 9 & $19,30 a$ & $18,37 b$ & $12,84 a$ & $177,91 a$ & $95,17 b$ & $7,20 d$ & $27,80 a$ & $11,14 a$ & $60,46 a$ \\
CTC 15 & $17,39 c$ & $16,22 d$ & $14,42 b$ & $157,81 c$ & $93,19 c$ & $8,65 b$ & $28,57 a$ & $09,28 a$ & $56,15 a$ \\
RB925345 & $19,94 a$ & $19,00 a$ & $14,17 b$ & $183,79 a$ & $95,29 b$ & $7,05 d$ & $27,41 b$ & $07,08 b$ & $37,28 b$ \\
RB867515 & $18,32 b$ & $17,20 c$ & $13,86 b$ & $167,00 b$ & $93,70 c$ & $6,75 d$ & $29,80 a$ & $06,87 b$ & $38,97 b$ \\
RB855453 & $18,63 b$ & $17,37 c$ & $13,48 a$ & $168,76 b$ & $93,25 c$ & $10,25 a$ & $26,25 b$ & $10,29 a$ & $59,16 a$ \\
RB925211 & $19,65 a$ & $19,03 a$ & $12,85 a$ & $183,73 a$ & $96,90 a$ & $8,80 b$ & $28,99 a$ & $09,73 a$ & $50,42 a$ \\
SP813250 & $18,42 b$ & $17,29 c$ & $13,24 a$ & $167,92 b$ & $93,89 c$ & $9,15 b$ & $28,21 a$ & $08,88 a$ & $51,38 a$ \\
SP891115 & $19,34 a$ & $18,49 b$ & $11,35 a$ & $178,96 a$ & $95,66 b$ & $9,35 b$ & $30,51 a$ & $12,25 a$ & $66,56 a$ \\
SP801842 & $18,48 b$ & $17,42 c$ & $13,98 b$ & $168,95 b$ & $94,28 c$ & $8,15 c$ & $26,67 b$ & $07,54 b$ & $43,44 b$ \\
SP842025 & $17,22 c$ & $16,15 d$ & $14,46 b$ & $156,98 c$ & $93,76 c$ & $9,30 b$ & $25,93 b$ & $05,60 b$ & $34,90 b$ \\
\hline
\end{tabular}

Médias seguidas pela mesma letra, na coluna, pertencem ao mesmo grupo pelo teste de agrupamento de ScottKnott (1974), a 5\% de probabilidade.

Fonte: Elaboração dos autores.

Houve a formação de três grupos para os caracteres Brix e ATR (Tabela 2). As cultivares apresentaram um desempenho idêntico com relação à formação de grupos para esses dois caracteres, o que já era esperado, pois o caráter ATR corresponde à quantidade de açúcar disponível na matéria-prima, diretamente relacionado com o valor de Brix. Segundo Silva et al. (2007), o Brix é uma medida importante como indicativo do teor de açúcar, cujos valores devem variar de 17 a 23\%, o que foi observado no presente trabalho para todas as cultivares avaliadas.

Com relação à variável Pol, de acordo com Fernandes (2011), a cana, para ser considerada madura, deve apresentar Pol de, no mínimo, 15,3\% no transcorrer da safra. Portanto, pode-se afirmar que todas as cultivares foram colhidas maduras, pois apresentaram valores médios superiores a esse percentual no momento da colheita (Tabela 2). As médias dos genótipos foram menos homogêneas para esse caráter, com a formação de quatro grupos, abrangendo apenas três cultivares no 
grupo de melhores médias (CTC 7, RB925345 e RB925211). Para Ferreira et al. (2007), deve-se dar atenção especial ao caráter Pol, pois, juntamente com o caráter $\mathrm{TCH}$, ele condiciona o quanto de açúcar será produzido em um hectare.

Para o caráter Fibra, houve variação entre 11,35 e 15,34\% das cultivares em estudo e a formação de três grupos (Tabela 2). A fibra é a parte sólida da planta de cana, a qual é formada por celulose, hemicelulose, ligninas, pectinas, entre outros componentes (RAVANELI et al., 2004). O valor do percentual de fibra é de fundamental importância no contexto da qualidade da matéria-prima da cana-de-açúcar, seja ela destinada para a alimentação animal ou para a agroindústria, e o grupo que apresentou o pior resultado para esse caráter foi composto pelos materiais CTC. Vale ressaltar que, de acordo com Andrade et al. (2002), teores de fibra mais baixos são desejados, pois no processo de extração do caldo para a produção de cachaça artesanal e outros produtos, em engenhos de baixa capacidade de extração, teores de fibra elevados comprometem a eficiência do processo. Além disso, para Silva et al. (2007), a fração fibrosa apresenta baixa taxa de extensão e degradação no rúmen dos bovinos, limitando o consumo de alimentos e o desempenho dos animais quando a cana-de-açúcar é utilizada como forragem.

Ocorreu a formação de apenas três grupos de média para o caráter industrial Pureza (Tabela 2). A cultivar RB925211 destacou-se entre as demais, ficando isolada como a de melhor média para esse caráter. Como a pureza expressa a porcentagem que a sacarose representa no caldo, ela é um indicativo da quantidade de açúcar em relação aos demais sólidos solúveis presentes no líquido. Segundo Fernandes (2011), esse caráter deve ser de, no mínimo, 85\% no decorrer da safra para uma boa industrialização da cana. Os genótipos avaliados apresentaram valores bem superiores ao recomendado, uma vez que, para todas as cultivares avaliadas, os valores desse caráter estiveram acima de $92 \%$, denotando uma alta pureza e a consequente possibilidade de altos rendimentos no processamento do caldo.

Para o caráter agronômico NC, houve uma grande variação entre os genótipos, com extremos de 6,75 e 10,30 colmos por metro linear ${ }^{1}$ para as cultivares RB867515 e CTC 16, respectivamente (Tabela 2). As cultivares que apresentaram os maiores valores para essa característica foram CTC 16, CTC 14 e RB855453. De acordo com Silva (2008), o desenvolvimento da cana-de-açúcar relaciona-se positivamente a um maior perfilhamento, o qual resulta em uma maior produtividade. Isso pode ser comprovado no presente trabalho, pois os genótipos mais produtivos (que apresentaram maior TCH) figuraram também no grupo daqueles que apresentaram o maior número de colmos (NC). Já para o atributo agronômico DC, houve a formação de apenas dois grupos, com um valor médio de 27,66 mm (Tabela 2). Para Marafon (2012), os caracteres número e diâmetro de colmos podem estar diretamente relacionados ao acúmulo de sacarose; por essa razão, Ferreira et al. (2007) ressaltaram que a seleção dos melhores genótipos, quanto à produção de cana-de-açúcar, pode ser realizada com base nesses dois caracteres.

Para os caracteres TPH e TCH, houve a formação de apenas dois grupos (Tabela 2). Como o caráter TPH está diretamente relacionado com o TCH, os grupos formados para ambos os caracteres foram compostos por praticamente as mesmas cultivares. Segundo Jackson et al. (1995), Marafon (2012) e Ferreira et al. (2007), o caráter TCH é um dos principais componentes de produção e deve sempre ser foco nos programas de melhoramento genético, razão pela qual deve ser mais detalhado e discutido em trabalhos de avaliação de cultivares. 0 valor da média para esse caráter foi de apenas 46,41 t ha-1 (Tabela 2), que é 33,1\% inferior à média nacional para a safra 2012/2013 $\left(69,407\right.$ t ha $\left.{ }^{-1}\right)$, de acordo com a CONAB (2014). Isso se deve principalmente à baixa produção da cana no primeiro ano de cultivo, que 
normalmente apresenta um sistema radicular pouco desenvolvido e também ao fato de a precipitação pluviométrica - embora acima da média histórica no ano agrícola ( $1.598 \mathrm{~mm}$ ) - ter sido mal distribuída durante o período de cultivo, apresentando um acumulado de $1.065 \mathrm{~mm}$ em apenas três meses (novembro, dezembro e janeiro). Ademais, houve a ocorrência de ventos fortes na área experimental durante 0 ciclo de cultivo e pouca luminosidade, o que comprometeu o metabolismo e, consequentemente, a produtividade da cultura.

$\mathrm{Na}$ Tabela 3, a seguir, estão apresentadas as correlações fenotípicas estimadas de nove caracteres avaliados. A magnitude dos coeficientes de correlação variou de $-0,73$ a 0,99. Das associações obtidas, os caracteres NC e DC não se correlacionaram de forma significativa com os demais caracteres avaliados, ou seja, não houve a contribuição deles para a expressão dos demais caracteres no nível de significância adotado. Isso contradiz o preconizado por Marafon (2012) e Silva et al. (2007), segundo os quais as características morfológicas, número de perfilhos e diâmetro dos colmos estão diretamente relacionados ao acúmulo de sacarose e produtividade da cana-de-açúcar.

Tabela 3. Estimativas dos coeficientes de correlação de Pearson entre os caracteres Brix\% caldo, Pol\% cana, Fibra\% cana, açúcar total recuperável (ATR), Pureza\% caldo, número de colmos $\mathrm{m}^{-1}$ (NC), diâmetro médio de colmo (DC), tonelada de pol por hectare (TPH) e tonelada de cana por hectare (TCH) de dezesseis cultivares de cana-de-açúcar, avaliadas no município de Lavras, MG, na safra de 2012.

\begin{tabular}{|c|c|c|c|c|c|c|c|c|}
\hline Caractere & $\mathrm{TCH}$ & Fibra & Brix & Pureza & NC & $\mathrm{DC}$ & Pol & TPH \\
\hline ATR & $0,42^{\text {ns }}$ & $-0,56^{*}$ & $0,99 * *$ & $0,85^{* *}$ & $-0,07^{\mathrm{ns}}$ & $0,20^{\text {ns }}$ & $0,99 * *$ & $0,58 *$ \\
\hline $\mathrm{TCH}$ & & $-0,67 * *$ & $0,43^{\text {ns }}$ & $0,26^{\mathrm{ns}}$ & $0,39^{\text {ns }}$ & $0,26^{\text {ns }}$ & $0,41^{\text {ns }}$ & $0,98 * *$ \\
\hline Fibra & & & $-0,57^{*}$ & $-0,39^{\text {ns }}$ & $-0,13^{\mathrm{ns}}$ & $-0,40^{\text {ns }}$ & $-0,56^{\mathrm{ns}}$ & $-0,73 * *$ \\
\hline Brix & & & & $0,79 * *$ & $-0,07^{\mathrm{ns}}$ & $0,18^{\text {ns }}$ & $0,99 * *$ & $0,59 *$ \\
\hline Pureza & & & & & $0,04^{\text {ns }}$ & $0,24^{\text {ns }}$ & $0,86 * *$ & $0,43^{\text {ns }}$ \\
\hline NC & & & & & & $-0,52^{\text {ns }}$ & $0,07^{\text {ns }}$ & $0,32^{\text {ns }}$ \\
\hline DC & & & & & & & $0,20^{\text {ns }}$ & $0,31^{\text {ns }}$ \\
\hline Pol & & & & & & & & $0,58 *$ \\
\hline
\end{tabular}

ns, **, *, não significativo, significativo a $1 \%$ e a $5 \%$ de probabilidade, respectivamente, pelo teste de t.

Fonte: Elaboração dos autores.

O caráter tecnológico Fibra correlacionou-se negativamente com os demais atributos avaliados (Tabela 3). A associação desse caráter e os caracteres TCH $(-0,67)$ e TPH $(-0,73)$ foi significativa a $1 \%$ de probabilidade, enquanto, para os caracteres ATR e Brix, foi significativa a $5 \%$. Esse fato demonstra que cultivares com um maior teor de fibra reduz, ao mesmo tempo, a produção e a qualidade da matéria-prima da cana-de-açúcar. Resultado similar foi obtido por Farias et al. (2009), em estudo da qualidade industrial de cana-de-açúcar sob diferentes lâminas de irrigação e adubação com Zinco, quando os autores observaram correlações negativas e altamente significativas entre o teor de fibra e os caracteres Pureza e ATR. Observa-se, na Tabela 3, que o aumento do caráter TPH está positivamente relacionado com a tonelagem de colmo por hectare (TCH) e ao valor de Pol, o que já era esperado, pois no cálculo da TPH consideram-se esses dois atributos.

Com relação aos atributos tecnológicos Brix, Pureza e Pol, houve correlações positivas e significativas em nível de $1 \%$ de probabilidade na correlação par a par entre esses três caracteres, o que confirma a associação direta entre eles (Tabela 3). Resultado similar foi obtido por Dalchiavon et al. (2014), os quais também obtiveram correlações de Pearson altamente significativas e positivas entre esses três caracteres avaliados na cultura da cana-de-açúcar. 
Os resultados obtidos para a análise do índice de seleção de Mulamba e Mock (1978) para os caracteres de maior interesse (TCH, Pol, Fibra e ATR) estão apresentados na Tabela 4.

Tabela 4. Índice de soma de postos de Mulamba e Mock (1978) para os caracteres tonelada de cana por hectare (TCH), Pol\% cana, Fibra\% cana e açúcar total recuperável (ATR) de dezesseis cultivares de cana-deaçúcar, avaliadas no município de Lavras, MG, na safra de 2012.

\begin{tabular}{cccccc}
\hline Cultivares & TCH & Pol & Fibra & ATR & Soma de postos \\
\hline SP891115 & 1 & 4 & 1 & 4 & 10 \\
RB925211 & 6 & 1 & 4 & 2 & 13 \\
CTC 9 & 2 & 5 & 3 & 5 & 15 \\
CTC 7 & 7 & 3 & 7 & 3 & 20 \\
RB855453 & 3 & 7 & 6 & 7 & 23 \\
RB925345 & 13 & 2 & 11 & 1 & 27 \\
SP813250 & 5 & 9 & 5 & 9 & 28 \\
SP801842 & 10 & 6 & 10 & 6 & 32 \\
CTC 2 & 9 & 11 & 2 & 11 & 33 \\
RB867515 & 11 & 10 & 9 & 10 & 40 \\
CTC 16 & 12 & 8 & 14 & 8 & 42 \\
CTC 15 & 4 & 14 & 12 & 14 & 44 \\
CTC 14 & 8 & 12 & 15 & 12 & 47 \\
CTC 8 & 15 & 13 & 8 & 13 & 49 \\
SP842025 & 14 & 16 & 13 & 16 & 59 \\
CTC 1 & 16 & 15 & 16 & 15 & 62 \\
\hline
\end{tabular}

Fonte: Elaboração dos autores.

Para Pedrozo et al. (2009), uma das estratégias utilizadas na seleção no processo de melhoramento genético da cana-de-açúcar é a correlação de caracteres. Porém, essa seleção pode ser inadequada, pois correlações negativas ou baixas entre os caracteres de interesse podem ser observadas, o que foi visto no presente trabalho para NC e DC. Por isso, a estratégia via índice de seleção é indicada, por permitir a classificação correta dos genótipos, considerando diversos caracteres simultaneamente.

Ao analisar o ranqueamento realizado pelo índice de soma de postos (Tabela 4), verifica-se que as três melhores cultivares foram a SP891115, RB925211 e CTC9, pois, de acordo com Cruz et al. (2004), quanto menor for o valor obtido na soma de postos, melhor é o desempenho da cultivar em relação às características avaliadas. Esse resultado é coincidente com o agrupamento de médias das melhores cultivares, nos diferentes caracteres avaliados, apresentado na Tabela 2, pois os melhores genótipos, agrupados em grupos de interesse, também figuraram entre aqueles de menor índice de seleção.

\section{Conclusão}

Houve uma grande variabilidade genética entre as cultivares de cana-de-açúcar avaliadas, resultando, consequentemente, na formação de vários grupos de caracteres para os tratamentos genéticos avaliados.

Os caracteres tecnológicos Brix, Pureza e Pol estão positivamente associados. 
Houve uma associação negativa entre o teor de Fibra e os demais caracteres agronômicos e industriais em estudo. As cultivares SP891115, RB925211 e CTC9 foram as mais promissoras quanto aos caracteres agroindustriais TCH, Pol, Fibra e ATR e poderão ser indicadas para o cultivo comercial na região de Lavras.

\title{
Agradecimentos
}

À Bocaina Agroindústria e Comércio de Cachaça Ltda., pela cessão da área experimental e apoio na condução do experimento.

Ao Instituto Agronômico de Campinas (IAC), pela realização das análises tecnológicas do presente estudo.

\section{Selection of potential sugarcane cultivars for Lavras, Minas Gerais, Brazil}

\begin{abstract}
The sugarcane crop plays an important economic role in the region of Lavras, Minas Gerais, Brazil, where it is grown without a great deal of technological assistance and with cultivars not adapted to local edaphic and climatic conditions. The aim of this study was to evaluate sugarcane cultivars in regard to agro-industrial yield potential in the southern region of Minas Gerais as well as to study the association between the agronomic and industrial traits in the first cutting. The experiment was conducted in Lavras, MG, where 16 cultivars were recommended for the sugar/ethanol industry in 4 x 4 quadruple lattice design experiment. The results showed that there was a great deal of genetic variability among the cultivars, which led to the formation of various groups of agro-industrial traits for the genotypes evaluated. The genotypes that exhibited greater fiber content also exhibited lower yield and lower quality of sugarcane raw material. The SP891115, RB925211 and CTC9 cultivars exhibited better performance in regard to the agro-industrial traits of tons of sugarcane per hectare (TSH), Pol, Fiber and total recoverable sugar (TRS), and they may be recommended for commercial growing in Lavras area.
\end{abstract}

Keywords: Saccharum spp. Yield. Correlation. Selection Index.

\section{Referências}

ALMEIDA, L. M.; VIANA, A. P.; AMARAL JÚNIOR, A. T. do; CARNEIRO JÚNIOR, J. de B. Melhoramento em famílias de irmãos-completos de cana-de-açúcar usando índices de seleção. Ciência Rural, Santa Maria, v. 44, n. 4, p. 605-611, abr. 2014. Disponível em: <http://www.scielo.br/pdf/ cr/v44n4/a10214cr2013-0596.pdf>. Acesso em: 8 ago. 2014.

ANDRADE, L. A. de B.; ANJOS, I. A. dos; FIGUEIREDO, P. A. M. de; QUINTELA, A. C. R. Utilização de variedades selecionadas de cana-de-açúcar na produção de cachaça de alambique. Informe Agropecuário, Belo Horizonte, v. 23, n. 217, p. 33-36, 2002.

ANJOS, I. A.; ANDRADE, L. A. de B.; GARCIA, J. C.; FIGUEIREDO, P. A. M. de.; CARVALHO, G. J. de. Efeitos da adubação orgânica e da época de colheita na qualidade da matéria-prima e nos rendi- 
mentos agrícola e de açúcar mascavo artesanal de duas cultivares de cana-de-açúcar (cana-planta). Ciência e Agrotecnologia, Lavras, v. 31, n. 1, p. 59-63, jan./fev. 2007. Disponível em: <http://www. scielo.br/pdf/cagro/v31n1/v31n1a09.pdf>. Acesso em: 17 ago. 2014.

CARGNELUTTI FILHO, A.; BRAGA JUNIOR, R. L. do C.; DAL'COL LÚCIO, A. Medidas de precisão experimental e número de repetições em ensaios de genótipos de cana-de-açúcar. Pesquisa agropecuária brasileira, Brasília, v. 47, n. 10, p. 1413-1421, out. 2012. Disponível em: <http://seer.sct. embrapa.br/index.php/pab/article/view/12890/8136>. Acesso em: 22 set. 2014.

CASTRO, H. S. de. ANDRADE, L. A. de B.; BOTREL, E. P.; EVANGELISTA, A. R. Rendimentos agrícola e forrageiro de três cultivares de cana-de-açúcar (Saccharum spp.) em diferentes épocas de corte. Ciência e Agrotecnologia, Lavras, v. 33, n. 5, p. 1336-1341, set./out. 2009. Disponível em: <http:// www.scielo.br/pdf/cagro/v33n5/v33n5a20.pdf > . Acesso em: 13 ago. 2014.

COMPANHIA NACIONAL DE ABASTECIMENTO (CONAB). Acompanhamento da safra brasileira de cana-de-açúcar: safras 2013/2014, quarto levantamento Abril/2014. Disponível em: <http://www. conab.gov.br/OlalaCMS/uploads/arquivos/14_04_10_09_00_57_boletim_cana_portugues_-_40_ lev___13.pdf>. Acesso em: 4 out. 2014.

CONSELHO DOS PRODUTORES DE CANA-DE-AÇÚCAR, AÇÚCAR E ÁLCOOL DO ESTADO DE SÃO PAULO (CONSECANA). Manual de instruções. 5. ed. Piracicaba, 2006. Disponível em: <http:// www.orplana.com.br/manual_2006.pdf>. Acesso em: 22 jul. 2013.

CRUZ, C. D.; REGAZZI, A. J.; CARNEIRO, P. C. S. Modelos biométricos aplicados ao melhoramento genético. 3. ed. Viçosa: UFV, 2004. 480p.

CRUZ, C. D. Programa genes: Biometria. Viçosa: Editora UFV, 2006. 382p.

DALCHIAVON, F. C.; CARVALHO, M. de P. e; MONTANARI, R.; ANDREOTTI, M.; PANOSSO, A. R. Produtividade da cana-de-açúcar: variabilidade linear e espacial entre componentes tecnológicos e da produção. Bioscience Journal, Uberlândia, v. 30, n. 3, p. 390-400, jun. 2014. Disponível em: <http://www.seer.ufu.br/index.php/biosciencejournal/article/view/18096/14551>. Acesso em: 2 out. 2014.

DANTAS, A. A. A.; CARVALHO, L. G. de; FERREIRA, E. Classificação e tendências climáticas em Lavras, MG. Ciência e Agrotecnologia, Lavras, v. 31, n. 6, p. 1862-1866, nov./dez. 2007. Disponível em: <http://www.scielo.br/pdf/cagro/v31n6/a39v31n6.pdf >. Acesso em: 1 out. 2014.

FARIAS, C. H. de A.; FERNANDES, P. D.; GHEYI, H. R.; DANTAS NETO, J. Qualidade industrial de cana-de-açúcar sob irrigação e adubação com zinco, em Tabuleiro Costeiro paraibano. Revista Brasileira de Engenharia Agrícola e Ambiental, Campina Grande, v. 13, n. 4, p. 419-428, jul./ago. 2009. Disponível em: <http://www.scielo.br/pdf/rbeaa/v13n4/v13n4a08.pdf>. Acesso em: 19 jul. 2014.

FERNANDES, A. C. Cálculos na Agroindústria da cana-de-açúcar. 3. ed. Piracicaba: STAB, 2011. $416 p$.

FERREIRA, F. M.; BARROS, W. S.; SILVA, F. L. da; BARBOSA, M. H. P.; CRUZ, C. D.; BASTOS, I. T. Relações fenotípicas e genotípicas entre componentes de produção em cana-de-açúcar. Bragantia, 
Campinas, v. 66, n. 4, p. 605-610, 2007. Disponível em: <http://www.scielo.br/pdf/brag/v66n4/10. pdf>. Acesso em: 3 set. 2014.

JACKSON, P.; MCRAE, T.; HOGARTH, M. Selection of sugarcane families across variable environments II. Patterns of response and association with environmental factors. Field Crops Research, v. 43, p. 119-130, Oct. 1995. Disponível em: <http://www.sciencedirect.com/science/article/pii /037842909500040W >. Acesso em: 30 set. 2014.

MARAFON, A. C. Análise quantitativa de crescimento em cana-de-açúcar: uma introdução ao procedimento prático. Documentos, n. 168. Aracajú, 2012. Disponível em: <http://www.cpatc.embrapa. br/publicacoes_2012/doc_168.pdf>. Acesso em: 8 ago. 2014.

MELO, L. J. O. T. de; OLIVEIRA, F. J. de; BASTOS, G. Q.; ANUNCIAÇÃO FILHO, C. J. da; REIS, O. V. dos. Desempenho agroindustrial de cultivares de cana-de-açúcar na zona da mata litoral sul de Pernambuco. Ciência e Agrotecnologia, Lavras, v. 33, n. 3, p. 684-691, mai./jun. 2009. Disponível em: <http://www.scielo.br/pdf/cagro/v33n3/a04v33n3.pdf>. Acesso em: 22 set. 2014.

MELO, L. J. O. T. de; OLIVEIRA, F. J. de; BASTOS, G. Q.; ANUNCIAÇÃO FILHO, C. J. da; REIS, O. V. dos. Interação genótipo x ciclos de colheita de cana-de-açúcar da zona da mata norte de Pernambuco. Bragantia, v. 65, n. 2, p. 197-205, 2006. Disponível em: <http://www.scielo.br/pdf/brag/ v65n2/30481.pdf>. Acesso em: 2 ago. 2014.

MULAMBA, N. N.; MOCK, J. J. Improvement of yield potential of the Eto Blanco maize (Zea mays L.) population by breeding for plant traits. Egypt Journal of Genetics and Cytology, Alexandria, v. 7, p. 40-51, 1978.

NASSIF, D. S. P.; MARIN, F. R.; COSTA, L. G. Padrões mínimos para coleta de dados experimentais para estudos sobre crescimento e desenvolvimento da cultura da cana-de-açúcar. Documentos, n. 127. Campinas, 2013. Disponível em: <http://www.infoteca.cnptia.embrapa.br/bitstream/ doc/970633/1/padroes.pdf $>$. Acesso em: 13 jul. 2014.

PEDROZO, C. A.; BENITES, F. R. G.; BARBOSA, M. H. P.; RESENDE, M. D. V. de; Eficiência de índices de seleção utilizando a metodologia REML/BLUP no melhoramento da cana-de-açúcar. Scientia Agraria, Curitiba, v. 10, n. 1, p. 31-036, jan./fev. 2009. Disponível em: <http://www.alice.cnptia. embrapa.br/bitstream/doc/304991/1/Deon.pdf>. Acesso em: 13 jul. 2014.

PERECIN, D.; LANDELL, M. G. de A.; XAVIER, M. A.; ANJOS, I. A. dos; BIDOIA, M. A. P.; SILVA, D. N. da. Progresso agronômico e genético em programa de melhoramento de cana-de-açúcar. Revista Brasileira de Biometria, São Paulo, v. 27, n. 2, p. 279-287, abr./jun. 2009. Disponível em: <http:// jaguar.fcav.unesp.br/RME/fasciculos/v27/v27_n2/Perecin.pdf>. Acesso em: 26 ago. 2014.

RAMAlHO, M. A. P.; ABREU, A. F. B.; SANTOS, J. B.; NUNES, J. A. R. Aplicações da genética quantitativa no melhoramento de plantas autógamas. Lavras: UFLA, 2012. 522p.

RAVANELI, G. C.; MUTTON, M. A.; MUTTON, M. J. R. Efeitos do desponte e das épocas de colheita sobre parâmetros tecnológicos em cana-de-açúcar. Científica, Jaboticabal, v. 32, n. 2, p. 185-190, 2004. Disponível em: <http://cientifica.org.br/index.php/cientifica/article/view/86/69>. Acesso em: 4 out. 2014. 
RESENDE, M. D. V.; DUARTE, J. B. Precisão e controle de qualidade em experimentos de avaliação de cultivares. Pesquisa Agropecuária Tropical, Goiânia, v. 37, n. 3, p. 182-194, set. 2007. Disponível em: <http://www.revistas.ufg.br/index.php/pat/article/viewFile/1867/1773>. Acesso em: 23 set. 2014.

RODRIGUES, R. C.; SOUZA, J. M. de; MARQUES, H. I. P.; BONOMO, R.; SCHMIDT, E. R. Produtividade e variáveis agroindustriais de cinco variedades de cana-de-açúcar no norte do Espírito Santo. Enciclopédia biosfera, Centro Científico Conhecer, Goiânia, v. 8, n. 15, p. 1443-1451, 2012. Disponível em: <http://www.conhecer.org.br/enciclop/2012b/ciencias\%20agrarias/produtividade\%20 e\%20variaveis.pdf>. Acesso em: 12 set. 2014.

SCOTT, A. J.; KNOTT, M. A. Cluster analysis method for grouping means in the analysis of variance. Biometrics, Washington, v. 30, n. 3, p. 507-512, sep.1974.

SILVA, E. A. da; FERREIRA, J. J.; RUAS, J. R. M.; PAES, J. M. V.; MACEDO, G. A. R. Utilização de cana-de-açúcar na alimentação de ruminantes. Informe Agropecuário, Belo Horizonte, v. 28, n. 239, p. 102-119, jul./ago. 2007.

SILVA, M. A. Interação genótipo x ambiente e estabilidade fenotípica de cana-de-açúcar em ciclo de cana de ano. Bragantia, Campinas, v. 67, n. 1, p. 109-117, 2008. Disponível em: <http://www. scielo.br/pdf/brag/v67n1/a13v67n1.pdf>. Acesso em: 13 ago. 2014.

STATISTICAL ANALYSIS SYSTEM (SAS). SAS/STATâ User's Guide. Version 8, Cary, NC: SAS Institute Inc. 1999.

\section{Histórico editorial}

Submetido em: 07/11/2014

Aceito em: 04/03/2015 